1 Craib KJP, Meddings DR, Strathdee SA, et al. Rectal gonorrhoea as an independent risk factor for HIV in a cohort of homosexual factor for HIV in a cohort of homo

2 Mertens TE, Hayes RJ, Smith PG. Epidemiological methods to study the interaction between HIV infection and other sex ually transmitted diseases. AIDS 1990 4:57-65.

3 Laga M, Mamadou TE, Bure A. Interrelationship of sexually transmitted disease and HIV: where are we now? AIDS 1994;8(suppl 1):s119-24.

4 van Griensven GJP, Koplin BA, Osmond D. Risk behaviour and HIV infection among younger homosexual men. AIDS 1994; 8(suppl 1):s125-30.

\section{A case cluster of possible tissue invasive} gonorrhoea

I read with great interest the report by Brook et al of a cluster of five cases of invasive gonococcal infection. ${ }^{1}$ The authors apparently are unaware of a similar report published over twenty years ago. ${ }^{2}$ We described a cluster in which a male patient with gonorrhoea infected seven of eight female contacts. Two other female partners could not be located. Among the seven infected women, two had disseminated gonococcal infection, four had pelvic inflammatory disease, and one had a Bartholin gland abscess. Three weeks after successful treatment of his urethritis, the male index case returned with disseminated gonococcal infection, having resumed intercourse with some of the same partners prior to their diagnosis and treatment.

In 1973 we lacked the ability to definitively prove that all of our patients were infected with the same strain of Neisseria gonorrhoeae. However, the epidemiologic circumstances made it clear that most or all of the patients in fact shared a common strain. We also cited several other reports from 1940 to 1972 that documented complications of gonococcal disease in couples or in mother-infant pairs. ${ }^{3-7}$ Collectively, these reports provided the first hint of variations in pathogenicity among gonococci.

There is nothing new under the sun (to coin a phrase)!

$$
\begin{array}{r}
\text { H. HUNTER HANDSFIELD } \\
\text { Harborview Medical Center } \\
325 \text { Ninth Avenue, Box } 359799 \\
\text { Seattle, Washington } \\
98104-2499 \\
\text { U.S.A. }
\end{array}
$$

1 Brook MG, Clark S, Stirland A, et al. A case cluster of possible tissue invasive gonorrhoea. Genitourin Med 1995;71:126-8.

2 Handsfield $\mathrm{HH}$, Holmes, KK. Microepidemic of virulent gonococcal infection. $\mathcal{f}$ Am Vener Dis Assoc 1974;1:20-2.

3 Abu-Nassar H, Hill N, Fred HL, et al. Cutaneous manifestations of gonococcemia. Cutaneous manifestations of gonoc
Arch Intern Med 1963;112:731-7.

4 Bjornberg A. Benign gonococcal sepsis: a report of 36 cases. Acta Dermatovenereol report of 36
$1970 ; 50: 313-6$.

5 Ackerman AB, Miller RC, Shapiro L. Gonococcemia and its cutaneous manifestations. Arch Dermatol 1965;91:227-32.

6 Parrish PP, Console WA, Battaglia J. Gonococcic arthritis of the newborn treated with sulfanilamide. $\mathcal{F A M A}$ 1940;114:241-2.

7 Gregory JE, Chisom JL, Meadows AT. Gonococcal arthritis in an infant. Br $\mathcal{F}$ Vener Dis 1974;1:306-7.
Pseudomonas aeruginosa infections and HIV

Ali, et $a l^{1}$ provide an interesting overview of their experience over a five year period with pseudomonas infections in HIV seropositive patients. Their report of an increase in the frequency of both pneumonic and septicaemic illness due to this organism concurs with other recent studies. Two points arise however, which merit further discussion. A report from this centre is incorrectly referenced ${ }^{2}$ as illustrating that pneumonias due to Staphylococcus aureus and nosocomially acquired gram-negative organisms occur with increased frequency in patients with indwelling central venous catheters (CVCs). In fact, what the quoted study demonstrated was an increased frequency of pseudomonas as an isolate in the blood cultures of HIV seropositive patients with septicaemia (found in 19 of 52), especially those with indwelling CVCs; in only two of these patients was there evidence of a pseudomonas pneumonia. In the same study an apparent association with concurrent CMV infection was cautiously suggested, but the results of Ali et al do not support this.

More importantly however, their conclusion that the use of systemic pneumo-cystis prophylaxis is an independent risk factor for the development of Pseudomonas aeruginosa pneumonia is erroneous and is not supported by the data provided. As the authors note, the affected patient group were all in the advanced stages of HIV disease with low CD4 counts. Not surprisingly therefore, the vast majority were also on Pneumocystis carinii (PCP) prophylaxis. However, without showing an increased risk for this group over a similarly severely immunosuppressed matched group not taking PCP prophylaxis (which for obvious reasons would be difficult to gather), this conclusion cannot be drawn. The low CD4 count, on the other hand, may be the relevant variable.

ORE MARK NEL SON Kobler Centre, St Stephen' Clinic, Chelsea and Westminster Healthcare Trust, 369 Fulham Road, London SW10 9TH, UK

1 Ali NJ, Kessel D, Miller RF. Bronchopulmonary infection with Pseudomonas aeruginosa in patients infected with human immunodeficiency virus. Genitourin Med 1995;71:73-7.

2 Nelson MR, Shanson DC, Barter GJ, Hawkins DA, Gazzard BG. Pseudomonas septicaemia associated with HIV. AIDS 1991;5:761-3.

Pneumococcal vaccine and HIV infection

Hellberg and colleagues" state "An association between cervical dyskaryosis, as well as the role of HPV in cervical cancer in situ and in invasive cancer, has been demonstrated." They quote Franceschi and colleagues ${ }^{2}$ in support of this claim.

Sheppard and colleagues ${ }^{3}$ report the psychological distress of patients diagnosed with genital warts, for whom "... there is the fear of the link between genital warts and cervical cancer".

The paper which is frequently quoted as establishing a link between genital warts and cervical cancer by Franceschi and colleagues $^{2}$ did no such thing. These authors studied women attending a genitourinary medicine clinic, who had smears taken.
Among the women attending with genital warts there was a significant excess of smears showing "superficial dyskaryosis". None of these women had evidence of high grade CIN and certainly none of them had cervical cancer. All of the more severe cytological abnormalities occurred in women with trichomonas and gonorrhoea.

Having performed this very preliminary study, two of the authors returned to Italy where they conducted a more rigorous study ${ }^{4}$, which demonstrated no evidence of an association between genital warts and subsequent carcinoma in situ or invasive cervical cancer. Ever since discovering the second negative paper it has always amazed me how widely quoted is the first paper by these authors, whilst the second is almost universally ignored. Is it because the first paper was in a British journal and the second one in an American journal? Did the first paper have a "snappier title" Or was it because the first paper confirmed people's prejudices and the second didn't? The original idea of an association was further refuted by our own work. 5

Could it be that the myth of genital warts needs the same treatment as the other myth about cervical cancer-that "it has been known for 150 years not to occur in virgins"-finally debunked in 1991 ?

MALCOLM GRIFFITHS Department of Obstetrics and Gynaecology Luton and Dunstable Hospital NHS Trust Lewsey Road, Luton, LU4 ODZ

1 Hellberg D, Borendal N, Sikstrom B, Nilsson $S$, Mardh P-A. Comparison of women with cervical human papillomavirus infection and genital warts. I. Some behavioural factors and clinical findings. Genitourin Med 1995; 71:88-91.

2 Franceschi S, Doll R, Galleway J, et al. Genital warts and cervical neoplasia: An epidemiological study. $\mathrm{Br} \underset{f}{ }$ Cancer 1983;48: logical

3 Sheppard S, White M, Walzman M. Genital warts: Just a nuisance? Genitourin Med 1995; 71:194-5.

4 la Vecchia C, Franceschi S, Decarli A. et al. Sexual factors, venereal disease and risk of intraepithelial and invasive cervical neoplasia. Cancer 1986;58:935-41.

5 Griffiths M, Sanderson D, Penna LK. Cervical epithelial abnormalities among women with warts- - more common warts-no more common than among controls.

6 Griffiths M. "Nuns, spinsters and virgins"Rigoni-Stern and cervical cancer revisited. $B$ f Obstet Gynaecol 1991;98:797-802.

Carcinoma of the penis: A cluster of cases in young men

The authors of the recent article Carcinoma of the penis in a HIV positive patient ${ }^{1}$ emphasise that this malignancy is rare in the immuno-competent population, especially in young men. Indeed, in 1989 (the most recent year for which figures are available) ${ }^{2}$ there were only 45 notified cases in men under the age of 50 years in England and Wales.

It may therefore be of interest to report that recently, in the space of seven months, no fewer than four apparently immunocompetent men presented to this department with ulcerating lesions, clinically suspicious of malignancy. The men's ages ranged from 34 to 48 years. Although none had a HIV test, they were all heterosexual with no high risk factors for HIV infection. Two of the four had clinical appearances suggestive of lichen sclerosus, a third had a history of genital warts and all were uncircumcised. 